\title{
Women's Mental Health: Menopause
}

\author{
By Jack M. Gorman, MD
}

Several years ago, I participated in a symposium on women's mental health in Washington, D.C. My topic was panic disorder, a condition about twice as common in women than in men. The large auditorium was filled with several hundred people. Each speaker, myself included, made an effort to point at that the illness they were discussing was either more common or more severe (or both) in women than in men. During the question and answer session a wise guy (of the male variety) stood up and asked: "What do you think would happen if we had a conference for people over the age of 100 ? I'll tell you what would happen. There wouldn't be any men here. It would be nothing but women because the men would all be dead. So the women must be doing something right after all."

Of course, his statement is not entirely true. Men can live beyond 100 years of age. Still, women live longer than men in general. My grandmother is 101 years old and my wife's grandmother is 108 years old. Both have been widows for many years.

Why, then, the focus on women's health?

The answer surely lies in the fact that women's health was largely ignored for so many years. Except for diseases of the female reproductive organs, most serious illnesses were studied exclusively in men. In part due to the Food and Drug Administration's former "fecund female" rule, by which women of childbearing age were automatically excluded from clinical trials involving medications or devices, most physicians do not realize that many of the older medications that we routinely use (eg, tricyclic antidepresants) were never formally studied in women under 50 years of age.

Beyond this, more complex reasons for the lack of research attention undoubtedly operated. Perhaps the knowledge that women live longer than men led the medical field to pretend that women do not die at all. Only recently has it been emphasized that myocardial infarction is the leading cause of death among American women. Hopefully, the days of a 55-yearold female coming to the emergency room complaining of crushing chest pain, shortness of breath, and sweating and being told that it must be anxiety are over; that woman needs an immediate electrocardiogram and cardiac enzyme determination.
From here we move on to the topic of this month's CNS Spectrums, menopause. The ratio of menopause folklore to science is very high. Some "authorities" insist we treat menopause as a benign, entirely normal stage in the life of a woman. Try telling that to a woman with daily hot flushes. To her, menopause is hardly benign and does not feel normal. Yet, we have very few validated methods for relieving hot flushes. There was substantial excitement several years ago when an antidepressant was shown to be effective for reducing the discomfort of hot flushes in a controlled trial. This was followed by profound disappointment when the company manufacturing the drug refused to pursue this indication. Apparently, the company did not feel this problem was important enough to address.

On the other hand, there are those who describe menopause in catastrophic terms. Women who experience menopause face crippling physical changes, the end of sexual activity, depression, and cognitive impairment. The once tried and true remedy, hormone replacement, is now regarded by many to be too dangerous for routine use by peri- and post-menopausal women. Suffering, these "experts" insist, is unavoidable.

The work assembled this month by Uriel Halbreich, MD, and Susan Kornstein, MD, is a welcome dose of reason and empiricism. This month's contribtors are willing to acknowledge three important things: menopause can be very uncomfortable for some women; most women get through menopause without debilitating physical or emotional consequences; and there is much we simply do not know about menopause, mostly due to a lack of scientific attention. Hopefully, this month's issue will serve as a psuh to help us discuss menopause openly, calmly, and scientifically.

I would also like to call your attention to the clinical column by CNS Spectrums' Mid-Atlantic editor, Dan J. Stein, MD, PhD. In "Placebo: The Best Pill of All," Dr. Stein shares an engaging clinical anecdote with important comments on the neurobiology of the placebo effect. Dr. Stein will continue writing columns like this over the coming months. I enjoyed reading his piece and hope you will as well. CNS

Dr. Gorman is the editor of this journal and Esther and Joseph Klingenstein Professor of Psychiatry and chair of the Department of Psychiatry at Mount Sinai School of Medicine in New York City. 